\title{
Regulator of G-protein signaling 5 enhances portal vein invasion in hepatocellular carcinoma
}

\author{
YUMI UMENO $^{1,2}$, SACHIKO OGASAWARA ${ }^{1}$, JUN AKIBA ${ }^{1}$, SATOSHI HATTORI $^{3}$, HIRONORI KUSANO ${ }^{1}$, \\ OSAMU NAKASHIMA ${ }^{4}$, HIRONORI KOGA ${ }^{5,6}$, TAKUJI TORIMURA ${ }^{5}$, RYOJI YAMAKAWA ${ }^{2}$ and HIROHISA YANO ${ }^{1}$ \\ Departments of ${ }^{1}$ Pathology and ${ }^{2}$ Ophthalmology, Kurume University School of Medicine; ${ }^{3}$ Biostatistic Center, \\ Kurume University; ${ }^{4}$ Department of Clinical Laboratory Medicine, Kurume University Hospital; ${ }^{5}$ Department of Medicine, \\ Division of Gastroenterology, Kurume University School of Medicine; ${ }^{6}$ Research Center for Innovative Cancer Therapy, \\ Liver Cancer Research Division, Kurume University, Kurume, Fukuoka 830-0011, Japan
}

Received October 23, 2015; Accepted February 17, 2017

DOI: $10.3892 / \mathrm{ol} .2017 .7474$

\begin{abstract}
Portal vein invasion (PVI) is a major prognostic factor in hepatocellular carcinoma (HCC). The aim of the present study was to identify molecules that regulate PVI. Sections of cancerous tissue, paired noncancerous tissue and the PVI area were collected from 3 frozen HCC sections, using laser microdissection. The present study focused on 3 upregulated molecules, integrin $\beta 3$ (ITGB3), secreted phosphoprotein 1 (SPP1) and regulator of G-protein signaling 5 (RGS5), and 2 molecules that were downregulated in PVI tissue compared with cancer tissue, metallothionein $1 \mathrm{G}$ (MT1G) and metallothionein $1 \mathrm{H}(\mathrm{MT} 1 \mathrm{H})$, as determined by cDNA microarray analysis. Reverse transcription-quantitative polymerase chain reaction analysis of $32 \mathrm{HCC}$ cases revealed that RGS5 mRNA levels were significantly increased and MT1 G and MT1H mRNA levels were significantly decreased in cancerous tissue compared with noncancerous tissue. However, there was no significant difference in ITGB3 and SPP1 expression. There were no significant differences between the expression of these molecules and any clinicopathologic factors, including PVI. Immunohistochemical staining for RGS5 in $60 \mathrm{HCC}$ cases demonstrated that RGS5 protein levels were higher in cancerous tissue compared with paired noncancerous tissue in $63.3 \%$ of HCC cases. Furthermore, high expression of RGS5 in cancerous tissue was significantly associated with PVI and tended to be associated with intrahepatic metastasis. Confluent multinodular type was significantly more frequent in cases with high expression of RGS5 in the cancerous tissue.
\end{abstract}

Correspondence to: Dr Jun Akiba, Department of Pathology, Kurume University School of Medicine, 67 Asahi-machi, Kurume, Fukuoka 830-0011, Japan

E-mail: akiba@med.kurume-u.ac.jp

Key words: cDNA microarray, hepatocellular carcinoma, laser microdissection, portal vein invasion, regulator of G-protein signaling 5
Therefore, RGS5 may be a useful prognostic biomarker as well as a potential target of molecular therapy to treat HCC.

\section{Introduction}

Hepatocellular carcinoma (HCC) is one of the most common cancers globally. High-risk screening and early detection have improved the prognosis of patients with HCC. However, the prognosis of advanced HCC remains poor despite the introduction of molecular targeted therapies. Portal vein invasion (PVI) is a major prognostic factor and is associated with intrahepatic metastasis and recurrence following curative resection. Des- $\gamma$-carboxyprothrombin (DCP) levels and/or macroscopic findings, including simple nodular type tumors with extranodular growth and confluent multinodular type tumors, have been reported to be associated with PVI (1-4). Several molecules, including ubiquitin-conjugating enzyme E2C (5), importin- $\alpha 1$ (6), lysosomal-associated transmembrane protein $4 \beta-35(7)$, protein tyrosine phosphatase type IVA3 (8) and caveolin-1 (9), are reported to be associated with PVI. However, the precise mechanisms involved in the regulation of PVI remain to be elucidated. Therefore, identification of the molecules regulating PVI is expected to contribute to the development of new molecular targeting therapies.

In the present study, molecules regulating PVI were probed using laser microdissection (LMD) and cDNA microarray analysis, and the role of these molecules in human HCC samples was evaluated.

\section{Materials and methods}

Ethics statement. The present study was approved by the Ethics Committee of Kurume University (Kurume, Japan; approval no. 13029). Written informed consent was obtained for cases from 2013. The Ethics Committee waived the requirement for written informed consent for cases from 2000 to 2004 as the data for these patients were retrospectively analyzed.

$L M D$. Frozen sections were obtained from 3 patients with HCC and PVI. All patients underwent curative hepatectomies for HCC at Kurume University Hospital (Kurume, Japan) 
from January 2013 to March 2013. All patients were male; the patients were 59, 68 and 76 years old. No treatment prior to surgery had been conducted in all patients.

Cancerous tissue with the PVI and paired noncancerous tissue was immediately cut from the surgically resected livers and embedded in Tissue Tek O.C.T. compound (Sakura Finetek USA, Inc., Torrance, CA, USA). These samples were kept at $-80^{\circ} \mathrm{C}$ until use in the following procedure.

Sections $(16 \mu \mathrm{m})$ were cut from the frozen tissue and the sections were stained with $0.05 \%$ toluidine blue. Each area (cancerous, paired noncancerous and PVI area) was microdissected using an LMD system (Leica LMD6000, Leica Microsystems GmbH, Wetzlar, Germany; Fig. 1).

Gene expression microarrays. Total RNA in each of the 3 areas was extracted using an RNAqueous-Micro kit (Ambion; Thermo Fisher Scientific, Inc., Waltham, MA, USA) according to the manufacturer's protocol. The cRNA was amplified and labeled using a Low Input Quick Amp Labeling kit (Agilent Technologies, Inc., Santa Clara, CA, USA), and hybridized to a 60K Agilent 60-mer oligomicroarray (SurePrint G3 Human Gene Expression Microarray 8x60 K v2; Agilent Technologies, Inc., Santa Clara, CA, USA) according to the manufacturer's protocol. All hybridized microarray slides were scanned using an Agilent scanner (Agilent Technologies, Inc.). Relative hybridization intensities and background hybridization values were calculated using Agilent Feature Extraction software (9.5.1.1; Agilent Technologies, Inc.).

Data analysis and filter criteria. Raw signal intensities and flags for each probe were calculated from hybridization intensities (gProcessedSignal) and spot information (gIsSaturated, etc.), according to the procedures recommended by Agilent Technologies, Inc. The flag criteria on GeneSpring software, version 12 (Agilent Technologies, Inc.) was as follows: Absent (A), feature is not positive, significant or above background; marginal (M), feature is not uniform, is saturated, and is a population outlier; present $(\mathrm{P})$, others. The raw signal intensities of two samples were $\log _{2}$-transformed and normalized by quantile algorithm with the 'preprocessCore' library package (10) on Bioconductor software, version 2.12 (11).

Probes with the ' $\mathrm{P}$ ' flag were selected from the two samples. To identify up or downregulated genes, Z-scores (12) and ratios (non-log scaled fold-change) were calculated from the normalized signal intensities of each probe, for comparison between control and experimental samples. Then, criteria for regulated genes was established as follows: Upregulated genes were genes with a $\mathrm{Z}$-score $\geq 2.0$ and ratio $\geq 1.5$-fold, while downregulated genes had a Z-score $\leq-2.0$ and ratio $\leq 0.66$. A heat map was generated using MeV software, version 4.7.2 (13).

Reverse transcription-quantitative polymerase chain reaction $(R T-q P C R)$. Frozen cancerous tissue and paired noncancerous tissue samples were obtained from 32 cases of HCC. All patients underwent curative hepatectomies for HCC at Kurume University Hospital (Kurume, Japan) from January 2000 to December 2003. No patients received preoperative anticancer therapies, including transcatheter arterial embolization or radiofrequency ablation. Patients with recurrent $\mathrm{HCC}$ and multiple HCC nodules were excluded.
Total RNA from cancerous tissue and paired noncancerous tissue was extracted using TRIzol reagent (Invitrogen; Thermo Fisher Scientific, Inc.), and complementary DNA (cDNA) was synthesized using the Reverse Transcription System (Promega, Madison, WI, USA), according to the manufacturers' protocols. RT-qPCR was performed using a 7500 Real Time PCR System and TaqMan PCR Gene Expression Master Mix with Taqman PCR assay probe/primers for integrin $\beta 3$ (ITGB3; Hs01001469_m1), secreted phosphoprotein 1 (SPP1; Hs00959010_m1), regulator of G-protein signaling 5 (RGS5; Hs01591223_s1), metallothionein $1 \mathrm{G}$ (MT1G; Hs02578922_gH) and metallothionein 1H (MT1H; Hs00823168_g1); $\beta$-actin (Hs99999903-m1) was used as an internal control gene (all from Applied Biosystems; Thermo Fisher Scientific, Inc.). Thermocycler conditions were as follows: An initial incubation at $50^{\circ} \mathrm{C}$ for $2 \mathrm{~min}$, then $95^{\circ} \mathrm{C}$ for $10 \mathrm{~min}$, and then 45 cycles of $95^{\circ} \mathrm{C}$ for $15 \mathrm{sec}, 60^{\circ} \mathrm{C}$ for $1 \mathrm{~min}$. To compare the mRNA expression levels in cancerous and noncancerous tissue, and thus the relationships between mRNA expression levels and clinicopathological factors, relative gene expression levels normalized by $\beta$-actin were calculated using the $2^{-\Delta \Delta \mathrm{Cq}}$ method (14).

Morphological observations. Formalin-fixed, paraffin embedded (FFPE) 4- $\mu \mathrm{m}$ sections were deparaffinized with xylene and soaked in hematoxylin for $5 \mathrm{~min}$, followed by eosin for $5 \mathrm{~min}$, at room temperature. Morphological observations were conducted on these FFPE sections under a light microscope (low magnification $\mathrm{x} 40$ to high magnification $\mathrm{x} 400$; BX41; Olympus Corporation, Tokyo, Japan).

Immunohistochemistry. To further validate the expression of the candidate genes identified by cDNA microarrays at the protein level and their relationships with clinicopathologic factors, immunohistochemical staining was performed on $4-\mu \mathrm{m}$ FFPE tissue sections from 60 cases of $\mathrm{HCC}$, containing cancerous and noncancerous tissues, that were surgically resected at Kurume University Hospital (Kurume, Japan) between January 2000 and December 2004. Of these 60 cases, 29 were additionally used in the RT-qPCR analysis. No patients received preoperative anticancer therapies, including transcatheter arterial embolization or radiofrequency ablation, prior to surgical resection. Patients with recurrent $\mathrm{HCC}$ and multiple $\mathrm{HCC}$ nodules were excluded. Clinicopathological features of the 60 patients with HCC are summarized in Table I. Sections $(4 \mu \mathrm{m})$ were cut from the FFPE liver samples that contained cancerous tissue and paired noncancerous tissue.

For RGS5, the sections were deparaffinized and rehydrated with xylene and $100 \%$ graded ethanol, respectively. The sections were subsequently soaked in Target Retrieval Solution, pH 9 (Dako; Agilent Technologies, Inc.) and treated at $95^{\circ} \mathrm{C}$ in a pressure cooker for $40 \mathrm{~min}$. Immunohistochemical staining was performed using a CSA II system (Dako; Agilent Technologies, Inc.) according to the manufacturer's protocol, with minor modification. The modifications were as follows: Endogenous peroxidase activity was quenched by incubation in $\mathrm{H}_{2} \mathrm{O}_{2}$ for $30 \mathrm{~min}$. Nonspecific binding sites were blocked using a blocking solution for endogenous peroxidase (Dako; Agilent Technologies, Inc.) for $30 \mathrm{~min}$, then tissue sections were 


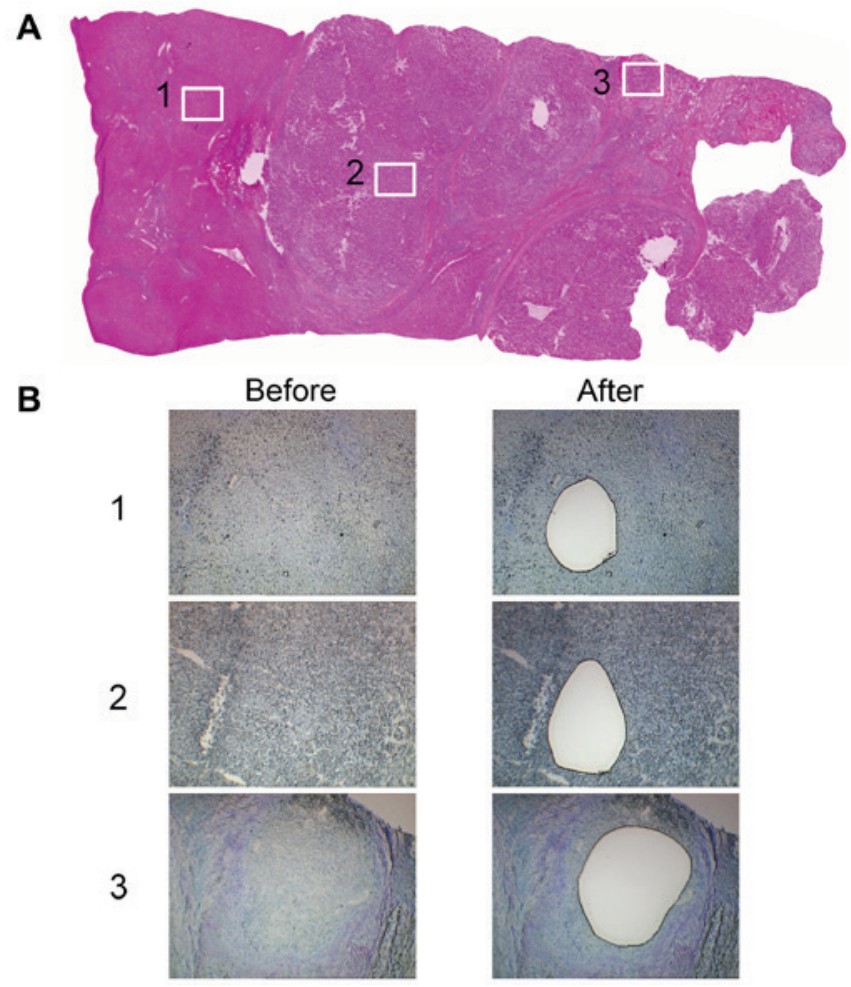

Figure 1. (A) Representative panoramic view of frozen tissue obtained from hepatocellular carcinoma with portal vein invasion, stained with hematoxylin and eosin. The areas indicated by rectangles 1, 2 and 3 correspond to (B), before and after laser microdissection, stained by toluidine blue.

incubated with the primary antibody for 15-60 min at room temperature. The primary antibody used was a mouse monoclonal anti-human RGS5 (clone, 1C1; cat no. NBP2-00880; dilution, 1:250; Novus Biologicals, LLC, Littleton, CO, USA).

The results of the staining were evaluated independently, according to the staining intensity and the percentage of positive cells, by two pathologists, using the previously described light microscope. Initially, the whole slide was observed at x40 magnification in order to assess the percentage of stained area. The staining intensity was then assessed at x200 magnification. The number of fields of view assessed depended on the stained area percentage. The staining intensity of the cancerous and PVI areas was scored on a scale from 0 to 3 compared with the noncancerous area, as follows: 0 , when the intensity in the cancerous area was equal to that of the noncancerous area; 1 , when the intensity in the cancerous area was slightly higher than that in the noncancerous area; 2, moderately higher and 3, markedly higher. The total expression score in the cancerous area was calculated by multiplying the staining intensity score by the percentage of stained area.

Statistical analysis. The Mann-Whitney U-test was used to examine the expression levels of ITGB3, SPP1, RGS5, MT1G and MT1H between noncancerous tissues and cancerous tissues, and to examine the association between expression levels of these molecules and clinicopathological factors. Associations among RGS5 expression, serum DCP levels, serum $\alpha$-fetoprotein (AFP) levels (as evaluated during routine practice, prior to the present study) and tumor size were examined by calculating Spearman's rank correlation coefficients.
Table I. Clinicopathological factors of the 60 cases of hepatocellular carcinoma.

\begin{tabular}{lc}
\hline Clinicopathological factor & Value \\
\hline Age (years; mean \pm SD) & $66.3 \pm 10.2$ \\
Sex (male/female) & $52 / 8$ \\
Serum AFP levels (ng/ml; mean \pm SD) & $1733.4 \pm 5872.1$ \\
Serum DCP levels (mAU/ml; mean \pm SD) & $3377.7 \pm 12947.7$ \\
Gross type, n (\%) & \\
SN & $39(65.0)$ \\
SNEG & $13(21.7)$ \\
CM & $7(11.7)$ \\
SNIM & $1(1.7)$ \\
Tumor size (mm; mean \pm SD) & $36.0 \pm 21.9$ \\
Histological grade, $\mathrm{n}(\%)$ & \\
Well-differentiated & $2(3.3)$ \\
Moderately-differentiated & $51(85.0)$ \\
Poorly-differentiated & $7(11.7)$ \\
Capsule formation, $\mathrm{n}(\%)$ & $45(75.0)$ \\
Capsule invasion, $\mathrm{n}(\%)$ & $43(71.7)$ \\
Portal vein invasion, $\mathrm{n}(\%)$ & $24(40.0)$ \\
Intrahepatic metastasis $\mathrm{n}(\%)$ & $9(15.0)$ \\
\hline
\end{tabular}

SD, standard deviation; AFP, $\alpha$-fetoprotein; DCP, des- $\gamma$-carboxyprothrombin; SN, simple nodular type; SNEG, simple nodular type with extranodular growth; $\mathrm{CM}$, confluent multinodular type; SNIM, small nodular type with indistinct margin.

Associations between RGS5 expression levels, serum DCP levels and serum AFP levels with clinicopathological factors were examined using Mann-Whitney U-tests. Logistic regression was used to determine whether RGS5 expression, serum DCP levels and serum AFP levels were associated with intrahepatic metastasis (IM) or PVI, adjusting for other clinicopathological factors including age, sex, histological grade and gross type. Furthermore, logistic regression was used to examine whether RGS5 expression, serum DCP levels and serum AFP levels were associated with gross type, adjusting for other clinicopathological factors. $\mathrm{P}<0.05$ was considered to indicate a statistically significant difference.

\section{Results}

cDNA microarray analysis. Upregulated or downregulated molecules in PVI tissue compared with cancerous tissue were detected by cDNA microarray analysis (Fig. 2). Only ITGB3 was upregulated in all $3 \mathrm{HCC}$ cases that were examined. On the other hand, MT1G and MT1H were downregulated in all 3 cases. Of the upregulated molecules in 2 cases with high Z-scores, SPP1 and RGS5 were selected. Integrins are a family of transmembrane receptors and SPP1 is a ligand of integrin $\alpha_{V} \beta_{3}$, which is a combination of integrin subunit $\alpha_{V}$ and $\beta_{3}$. RGS5 has been reported to be a marker of cancer-associated endothelial cells (15) and is an endothelial cell marker that is highly expressed in HCC (16). Therefore, ITGB3, SPP1, RGS5, MT1 G and MT1H were focused on by the present study. 


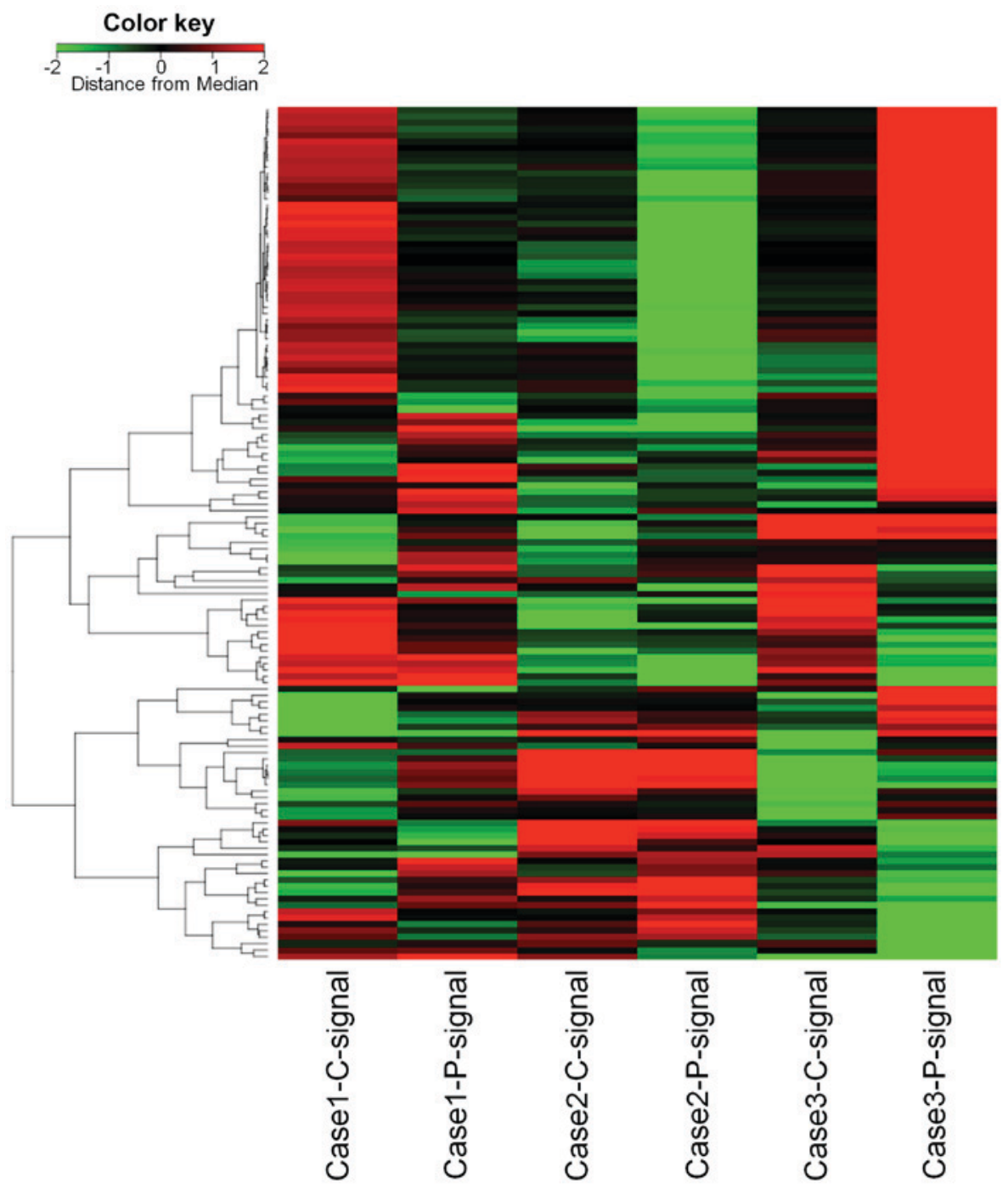

Figure 2. Heat map of the differentially expressed genes. A hierarchical clustering method was used to sort the genes. The color indicates the distance from the median of each row. The distance metric was the Pearson correlation, and the linkage method was average linkage clustering.
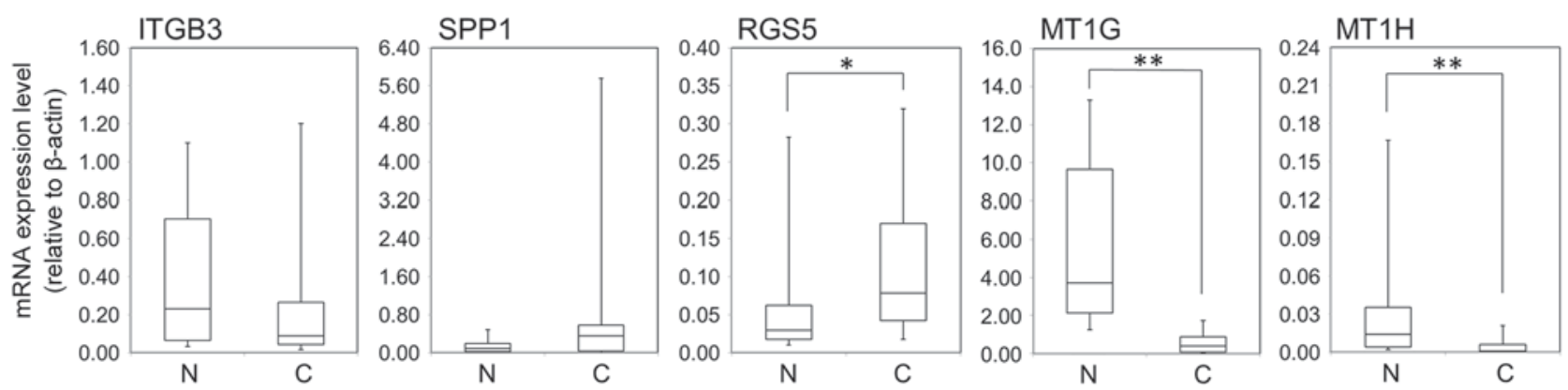

Figure 3. Comparison of ITGB3, SPP1, RGS5, MT1G and MT1H gene expression levels between N and C tissue. Capped bars represent the 10 and 90 th percentiles. " $\mathrm{P}<0.05$ and ${ }^{* *} \mathrm{P}<0.01$ vs. N. ITGB3, integrin $\beta 3$; SPP1, secreted phosphoprotein 1; RGS5, regulator of G-protein signaling 5; MT1 G, metallothionein $1 \mathrm{G}$; $\mathrm{MT} 1 \mathrm{H}$, metallothionein $1 \mathrm{H}$; N, noncancerous; $\mathrm{C}$, cancerous.

$R T-q P C R$ analysis. RGS5 was significantly overexpressed at the mRNA level in cancerous tissue compared with noncancerous tissue ( $\mathrm{P}=0.0196$; Fig. 3$)$. However, there was no significant difference in ITGB3 and SPP1 mRNA expression $(\mathrm{P}=0.1265$ and $\mathrm{P}=0.1165$, respectively; Fig. 3$)$. MT1G and MT1H mRNA expression levels were significantly lower in cancerous tissue compared with noncancerous tissue $(\mathrm{P}<0.01$;
Fig. 3). There were no significant associations between the expression of these molecules and any clinicopathological factors, including PVI.

RGS5 expression in HCC and clinicopathological factors. Immunohistochemical staining demonstrated that RGS5 protein expression was higher in cancerous tissue compared 
Table II. Summary of RGS5 expression by portal vein invasion, intrahepatic metastasis and clinicopathological factors.

\begin{tabular}{|c|c|c|c|c|c|c|c|}
\hline Clinicopathological factor & $\mathrm{n}$ & $\min$ & $\mathrm{q} 1$ & median & $\mathrm{q} 3$ & $\max$ & P-value \\
\hline Sex & & & & & & & 0.4891 \\
\hline Female & 8 & 0.1 & 0.15 & 0.4 & 0.75 & 1.3 & \\
\hline Male & 52 & 0 & 0 & 0.2 & 1.15 & 2.4 & \\
\hline Gross type & & & & & & & 0.0068 \\
\hline $\mathrm{SN}$ & 39 & 0 & 0 & 0.1 & 0.5 & 1.9 & \\
\hline SNEG & 13 & 0.1 & 0.5 & 1 & 1.3 & 2.1 & \\
\hline $\mathrm{CM}$ & 7 & 0 & 0 & 0.6 & 2.3 & 2.4 & \\
\hline SNIM & 1 & 0 & 0 & 0 & 0 & 0 & \\
\hline Histological grade & & & & & & & 0.0313 \\
\hline Well & 2 & 0 & 0 & 0.1 & 0.2 & 0.2 & \\
\hline Moderate & 51 & 0 & 0 & 0.2 & 1.1 & 2.4 & \\
\hline Poor & 7 & 0.3 & 0.4 & 0.6 & 1.8 & 2.1 & \\
\hline Portal vein invasion & & & & & & & 0.0025 \\
\hline- & 36 & 0 & 0 & 0.05 & 0.5 & 1.6 & \\
\hline+ & 24 & 0 & 0.15 & 0.8 & 1.45 & 2.4 & \\
\hline Intrahepatic metastasis & & & & & & & 0.1019 \\
\hline- & 51 & 0 & 0 & 0.2 & 1 & 2.4 & \\
\hline+ & 9 & 0 & 0.5 & 0.8 & 1.4 & 1.9 & \\
\hline
\end{tabular}

In testing for gross type and histological grade, subjects classified as SNIM and Well, respectively, were removed. RGS5, regulator of G-protein signaling 5; SN, simple nodular type; SNEG, simple nodular type with extranodular growth; CM, confluent multinodular type; SNIM, small nodular type with indistinct margin; Well, well-differentiated hepatocellular carcinoma; Moderate, moderately-differentiated hepatocellular carcinoma; Poor, poorly-differentiated hepatocellular carcinoma.

Table III. Logistic regression for portal vein invasion.

\begin{tabular}{|c|c|c|c|c|}
\hline Clinicopathological feature & Unit & OR & $(95 \% \mathrm{CI})$ & P-value \\
\hline Age & 10 & 1.209 & $(0.6-2.436)$ & 0.5949 \\
\hline Sex & Female/Male & 2.703 & $(0.379-19.288)$ & 0.3212 \\
\hline Histological grade & Mode/Poor & 0.264 & $(0.016-4.487)$ & 0.3569 \\
\hline Gross type & $\mathrm{SNEG}, \mathrm{CM} / \mathrm{SN}$ & 12.059 & $(2.664-54.586)$ & 0.0012 \\
\hline RGS5 & 1 & 2.359 & $(0.74-7.517)$ & 0.1466 \\
\hline AFP & 480 & 1.071 & $(0.957-1.197)$ & 0.2324 \\
\hline DCP & 500 & 0.968 & $(0.916-1.024)$ & 0.2576 \\
\hline
\end{tabular}

RGS5 expression, serum AFP levels and serum DCP levels were treated as continuous variables and units for the OR were determined referring to the difference between the upper and lower 25\% percentiles. OR, odds ratio; CI, confidence interval; RGS5, regulator of G-protein signaling 5; AFP, $\alpha$-fetoprotein; DCP, des- $\gamma$-carboxyprothrombin; Mode, moderately-differentiated hepatocellular carcinoma; Poor, poorly-differentiated hepatocellular carcinoma; SNEG, simple nodular type with extranodular growth; CM, confluent multinodular type; SN, simple nodular type.

with paired noncancerous tissue in $38 / 60$ (63.3\%) of HCC cases. RGS5 expression was observed in the cytoplasm. The average RGS5 expression score in cancerous tissue was $0.58 \pm 0.68$. RGS5 expression was significantly associated with PVI ( $\mathrm{P}=0.0025$; Table II) and tended to be associated with IM $(\mathrm{P}=0.1019$; Table II). Out of RGS5 expression, serum DCP levels and serum AFP levels, only RGS5 was significantly associated with gross type $(\mathrm{P}=0.0068$; Table II): RGS5 was higher in the confluent multinodular type. Spearman's rank correlation coefficients for RGS5 expression, serum DCP levels, serum AFP levels and tumor size revealed that RGS5 expression and serum AFP levels were significantly associated with each other $(\mathrm{r}=0.387 ; \mathrm{P}=0.0027)$, RGS5 expression was not associated with serum DCP levels or tumor size. On the other hand, serum DCP levels were significantly associated with tumor size $(r=0.596 ; \mathrm{P}<0.0001)$.

The results of the logistic regression analyses for PVI and IM were summarized in Tables III and IV, respectively. In these analyses, patients with well-differentiated type or small nodular type with an indistinct margin were excluded, since only a few 
Table IV. Logistic regression for intrahepatic metastasis.

\begin{tabular}{lcccr}
\hline Clinicopathological feature & Unit & OR & $(95 \%$ CI) & P-value \\
\hline Age & 10 & 1.274 & $(0.513-3.168)$ & 0.6021 \\
Sex & Female/Male & 0.468 & $(0.028-7.911)$ & 0.5984 \\
Histological grade & Mode/Poor & 1.048 & $(0.073-15.127)$ & 0.9726 \\
Gross type & SNEG, CM/SN & 4.57 & $(0.884-23.629)$ & 0.0698 \\
RGS5 & 1 & 1.517 & $(0.439-5.235)$ & 0.5098 \\
AFP & 480 & 1.052 & $(0.952-1.162)$ & 0.3184 \\
DCP & 500 & 0.991 & $(0.945-1.039)$ & 0.7012
\end{tabular}

RGS5 expression, serum AFP levels and serum DCP levels were treated as continuous variables and units for the OR were determined referring to the difference between the upper and lower 25\% percentiles. Firth's correction was employed to stabilize estimates. OR, odds ratio; CI, confidence interval; RGS5, regulator of G-protein signaling 5; AFP, $\alpha$-fetoprotein; DCP, des- $\gamma$-carboxyprothrombin; Mode, moderately-differentiated hepatocellular carcinoma; Poor, poorly-differentiated hepatocellular carcinoma; SNEG, simple nodular type with extranodular growth; $\mathrm{CM}$, confluent multinodular type; $\mathrm{SN}$, simple nodular type.

Table V. Logistic regression for gross type.

\begin{tabular}{lcccc}
\hline Clinicopathological feature & Unit & OR & $(95 \%$ CI $)$ & P-value \\
\hline Age & 10 & 1.175 & $(0.654-2.111)$ & 0.5905 \\
Sex & Female/Male & 0.74 & $(0.091-6.035)$ & 0.7786 \\
Histological grade & Mode/Poor & 0.654 & $(0.065-6.585)$ & 0.7184 \\
RGS5 & 1 & 3.628 & $(1.291-10.196)$ & 0.0145 \\
AFP & 480 & 0.928 & $(0.788-1.093)$ & 0.371 \\
DCP & 500 & 1.036 & $(0.968-1.108)$ & 0.3079 \\
\hline
\end{tabular}

RGS5 expression, serum AFP levels and serum DCP levels were treated as continuous variables and units for the OR were determined referring difference between upper and lower 25 percent percentiles. OR, odds ratio; CI, confidence interval; RGS5, regulator of G-protein signaling 5; AFP, $\alpha$-fetoprotein; DCP, des- $\gamma$-carboxyprothrombin; Mode, moderately-differentiated hepatocellular carcinoma; Poor, poorly-differentiated hepatocellular carcinoma.

patients were classified into these categories. Gross type was associated with PVI ( $\mathrm{P}=0.0012$; Table III), whereas RGS5 expression, serum DCP levels and serum AFP levels were not associated with PVI. No clear association was observed between IM and gross type ( $\mathrm{P}=0.0698$; Table IV). Logistic regression analysis for associations between gross type and other factors revealed that RGS5 expression was significantly associated with gross type ( $\mathrm{P}=0.0145$; Table $\mathrm{V})$, but not with serum $\mathrm{DCP}$ levels or serum AFP levels, upon adjusting for other clinicopathological factors. In addition, in 16/24 (66.7\%) cases of HCC with PVI, the staining intensity within the PVI area was equal to or stronger than that of cancerous tissue (Fig. 4).

\section{Discussion}

In the present study, noncancerous, cancerous and PVI areas were selected using the LMD method, and a comprehensive analysis of these samples was conducted using cDNA microarray techniques. Among the extracted molecules, RGS5 was demonstrated to potentially regulate PVI in HCC.

RGS5 is a member of the RGS protein family and RGS proteins act as GTPase-activating proteins for heterotorimeric
$\mathrm{G}$ protein $\alpha$ subunits, negatively regulating $\mathrm{G}$-protein signaling (17-19). RGS5 was reported to be expressed in the heart, lung, skeletal muscle and small intestine (20). It is also reported to be expressed in pericytes and vascular smooth muscle cells (21). With regard to RGS5 and cancer, RGS5 expression has been demonstrated to be positively correlated with the degree of tumor differentiation in gastric carcinoma (22).

The results of the present study support those of Hu et al (23) who also used RT-qPCR to analyze tissue from 20 patients with HCC and revealed that RGS5 expression was higher in cancerous tissue compared with noncancerous tissue, and that RGS5 expression was higher in liver cancer cell lines than in matched normal tissue. They also reported that recurrence and venous infiltration were more frequent and that disease-free survival was lower in 40 cases of HCC that overexpressed RGS5, as determined by RT-qPCR. The present study observed no significant difference in RGS5 expression at the mRNA level $(\mathrm{P}=0.1844)$, but immunohistochemical staining revealed that high RGS5 expression in cancer tissue was significantly correlated with PVI. There was also a tendency towards increased IM in cases with high RGS5 expression, 


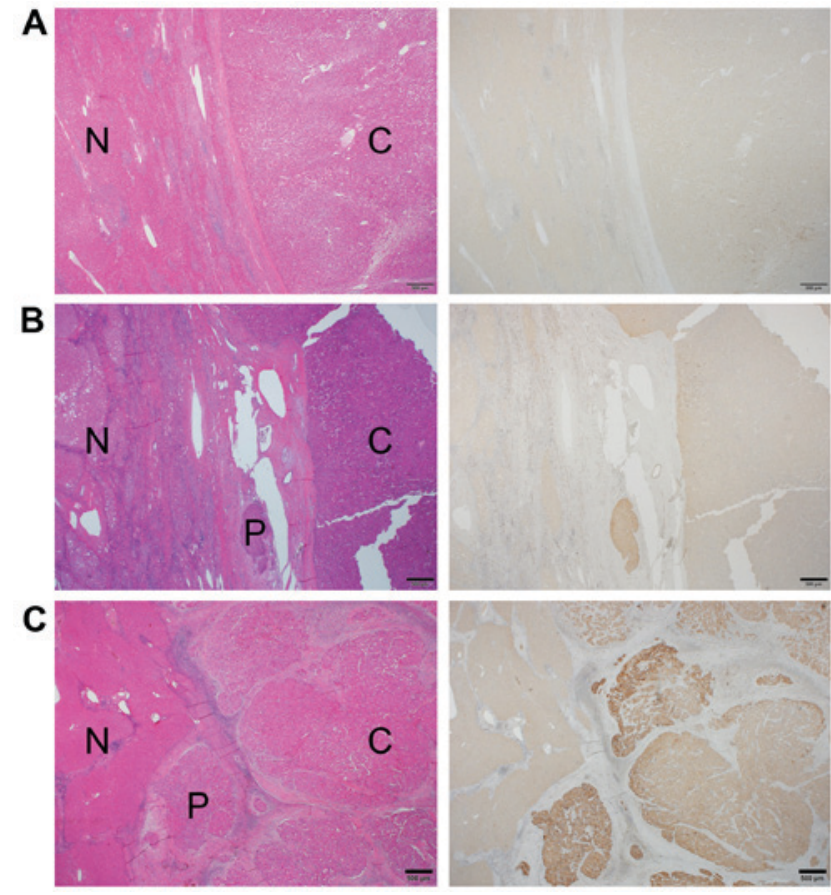

Figure 4. RGS5 protein expression in HCC cases, visualized with hematoxylin and eosin (left) and immunohistochemical staining (right). (A) A simple nodular type HCC case with equal RGS5 expression levels between $\mathrm{C}$ and $\mathrm{N}$ tissues. (B) A simple nodular type with extranodular growth and (C) a confluent multinodular type with stronger RGS5 expression levels in $\mathrm{C}$ tissues and in the $\mathrm{P}$ area compared with $\mathrm{N}$ tissue. Scale bar, $500 \mu \mathrm{m}$. RGS5, regulator of G-protein signaling 5; C, cancerous; $\mathrm{N}$, non-cancerous; P, portal vein invasion area.

although the difference was not statistically significant. One potential reason RGS5 expression was not significantly associated with PVI at the mRNA level may be that the number of cases examined by RT-qPCR was too small, consisting of only 29 of the 60 cases subjected to immunostaining. Furthermore, with regard to gross type, cases where immunostaining revealed high expression of RGS5 were significantly more likely to be confluent multinodular type HCC. The logistic regression analyses revealed that RGS5 expression was not an independent prognostic factor for PVI, whereas the gross type was. RGS5 was revealed to be associated with the gross type independently of other clinicopathological factors, indicating that RGS5 is involved in the determination of the gross type and thus may contribute to PVI. In HCC, gross classification as confluent multinodular type or nodular type with extranodular growth has frequently been associated with PVI (2-4), and these previous reports support the results of the present study; that RGS5 is associated with PVI.

Furuya et al (24) examined the localization of RGS5 by using in situ hybridization (ISH) in the kidney, and observed strong expression of RGS5 in vessels within tumor cell nests, but not in tumor cells or in endothelial cells of normal kidney vasculature. Immunohistochemical staining suggested that the primary location of RGS5 was tumor endothelial cells. Silini et al (15) reported higher levels of RGS5 mRNA in endothelial cells isolated from carcinomas, primarily ovarian carcinomas, compared with endothelial cells isolated from non-neoplastic tissue. In a study of hepatic tissue, Chen et al (16) used ISH to demonstrate that
RGS5 was not expressed in sinusoidal endothelial cells in non-tumor liver tissues, detected RGS5 mRNA in the sinusoidal endothelial cells in the HCC samples. The present study used immunohistochemical staining to reveal that RGS5 was expressed in the cytoplasm of HCC cells. Staining was not clearly observed in sinusoidal endothelial cells in the noncancerous and cancerous areas. Wang et al (22) performed immunohistochemical staining of RGS5 in gastric carcinoma and revealed that RGS5 was expressed in the cytoplasm of cancer cells. Huang et al (25) also reported RGS5 expression in the cytoplasm and the cell membrane of non-small cell lung cancer cells, using immunostaining. Furthermore, unpublished data from this laboratory used western blotting to observe RGS5 expression in an HCC cell line (data not shown), a result that supported the immunohistochemical staining results, which revealed RGS5 expression in HCC cells.

Furthermore, in $66.7 \%$ of the HCC cases with PVI, immunohistochemical staining intensity was as strong or stronger in the PVI tissue as in the cancerous tissue. Hu et al (23) reported that knockdown of RGS5 suppressed cell migration and invasion, suggesting that cancer cells with high RGS5 expression have increased invasive activity, including PVI.

In conclusion, RGS5 expression in cancerous tissues was significantly upregulated at the mRNA and protein levels compared with noncancerous tissue, and was significantly associated with PVI in HCC. RGS5 may therefore be a useful prognostic biomarker as well as a potential target for molecular therapy for the treatment of HCC.

\section{Acknowledgements}

The authors would like to thank Dr Hiroaki Miyoshi, Mr. Kazutaka Nakashima, Ms. Akiko Tanaka, Ms. Sachiyo Maeda, Ms. Yukina Maruyama and Ms. Akemi Fujiyoshi for their technical assistance.

\section{References}

1. Koike Y, Shiratori Y, Sato S, Obi S, Teratani T, Imamura M, Yoshida H, Shiina S and Omata M: Des-gamma-carboxy prothrombin as a useful predisposing factor for the development of portal venous invasion in patients with hepatocellular carcinoma: A prospective analysis of 227 patients. Cancer 91: 561-569, 2001.

2. Hui AM, Takayama T, Sano K, Kubota K, Akahane M, Ohtomo K and Makuuchi M: Predictive value of gross classification of hepatocellular carcinoma on recurrence and survival after hepatectomy. J Hepatol 33: 975-979, 2000.

3. Murakata A, Tanaka S, Mogushi K, Yasen M, Noguchi N, Irie T, Kudo A, Nakamura N, Tanaka H and Arii S: Gene expression signature of the gross morphology in hepatocellular carcinoma. Ann Surg 253: 94-100, 2011.

4. Sumie S, Kuromatsu R, Okuda K, Ando E, Takata A, Fukushima N, Watanabe Y, Kojiro M and Sata M: Microvascular invasion in patients with hepatocellular carcinoma and its predictable clinicopathological factors. Ann Surg Oncol 15: 1375-1382, 2008.

5. Ieta K, Ojima E, Tanaka F, Nakamura Y, Haraguchi N, Mimori K, Inoue H, Kuwano $\mathrm{H}$ and Mori M: Identification of overexpressed genes in hepatocellular carcinoma, with special reference to ubiquitin-conjugating enzyme E2C gene expression. Int J Cancer 121: 33-38, 2007.

6. Yoshitake K, Tanaka S, Mogushi K, Aihara A, Murakata A, Matsumura S, Mitsunori Y, Yasen M, Ban D, Noguchi N, et al: Importin- $\alpha 1$ as a novel prognostic target for hepatocellular carcinoma. Ann Surg Oncol 18: 2093-2103, 2011. 
7. Yang $H$, Xiong FX, Lin M, Yang Y, Nie X and Zhou RL: LAPTM4B-35 overexpression is a risk factor for tumor recurrence and poor prognosis in hepatocellular carcinoma. J Cancer Res Clin Oncol 136: 275-281, 2010.

8. Mayinuer A, Yasen M, Mogushi K, Obulhasim G, Xieraili M, Aihara A, Tanaka S, Mizushima H, Tanaka H and Arii S: Upregulation of protein tyrosine phosphatase type IVA member 3 (PTP4A3/PRL-3) is associated with tumor differentiation and a poor prognosis in human hepatocellular carcinoma. Ann Surg Oncol 20: 305-317, 2013.

9. Tang Y, Zeng X, He F, Liao Y, Qian N and Toi M: Caveolin-1 is related to invasion, survival and poor prognosis in hepatocellular cancer. Med Oncol 29: 977-984, 2012.

10. Bolstad BM, Irizarry RA, Astrand M and Speed TP: A comparison of normalization methods for high density oligonucleotide array data based on variance and bias. Bioinformatics 19: 185-193, 2003.

11. Gentleman RC, Carey VJ, Bates DM, Bolstad B, Dettling M, Dudoit S, Ellis B, Gautier L, Ge Y, Gentry J, et al: Bioconductor: Open software development for computational biology and bioinformatics. Genome Biol 5: R80, 2004.

12. Quackenbush J: Microarray data normalization and transformation. Nat Genet 32 (Suppl): S496-S501, 2002

13. Saeed AI, Sharov V, White J, Li J, Liang W, Bhagabati N, Braisted J, Klapa M, Currier T, Thiagarajan M, et al: TM4: A free, open-source system for microarray data management and analysis. Biotechniques 34: 374-378, 2003.

14. Livak KJ and Schmittgen TD: Analysis of relative gene expression data using real-time quantitative PCR and the 2(-Delta Delta C(T)) method. Methods 25: 402-408, 2001.

15. Silini A, Ghilardi C, Figini S, Sangalli F, Fruscio R, Dahse R, Pedley RB, Giavazzi R and Bani M: Regulator of G-protein signaling 5 (RGS5) protein: A novel marker of cancer vasculature elicited and sustained by the tumor's proangiogenic microenvironment. Cell Mol Life Sci 69: 1167-1178, 2012.
16. Chen X, Higgins J, Cheung ST, Li R, Mason V, Montgomery K, Fan ST, van de Rijn M and So S: Novel endothelial cell markers in hepatocellular carcinoma. Mod Pathol 17: 1198-1210, 2004.

17. Hepler JR: Emerging roles for RGS proteins in cell signalling. Trends Pharmacol Sci 20: 376-382, 1999.

18. Siderovski DP, Strockbine B and Behe CI: Whither goest the RGS proteins? Crit Rev Biochem Mol Biol 34: 215-251, 1999.

19. Zheng B, De Vries L and Gist Farquhar M: Divergence of RGS proteins: Evidence for the existence of six mammalian RGS subfamilies. Trends Biochem Sci 24: 411-414, 1999.

20. Seki N, Sugano S, Suzuki Y, Nakagawara A, Ohira M, Muramatsu M, Saito T and Hori T: Isolation, tissue expression, and chromosomal assignment of human RGS5, a novel G-protein signaling regulator gene. J Hum Genet 43: 202-205, 1998.

21. Bondjers C, Kalen M, Hellstrom M, Scheidl SJ, Abramsson A, Renner O,LindahlP, Cho H,Kehrl J and BetsholtzC: Transcription profiling of platelet-derived growth factor-B-deficient mouse embryos identifies RGS5 as a novel marker for pericytes and vascular smooth muscle cells. Am J Pathol 162: 721-729, 2003.

22. Wang JH, Huang WS, Hu CR, Guan XX, Zhou HB and Chen LB: Relationship between RGS5 expression and differentiation and angiogenesis of gastric carcinoma. World J Gastroenterol 16: $5642-5646,2010$

23. Hu M, Chen X, Zhang J, Wang D, Fang X, Wang X, Wang G, Chen $\mathrm{G}$, Jiang X, Xia H, et al: Over-expression of regulator of $\mathrm{G}$ protein signaling 5 promotes tumor metastasis by inducing epithelial-mesenchymal transition in hepatocellular carcinoma cells. J Surg Oncol 108: 192-196, 2013.

24. Furuya M, Nishiyama M, Kimura S, Suyama T, Naya Y, Ito H, Nikaido T and Ishikura $\mathrm{H}$ : Expression of regulator of $\mathrm{G}$ protein signalling protein 5 (RGS5) in the tumour vasculature of human renal cell carcinoma. J Pathol 203: 551-558, 2004.

25. Huang G, Song H, Wang R, Han X and Chen L: The relationship between RGS5 expression and cancer differentiation and metastasis in non-small cell lung cancer. J Surg Oncol 105: 420-424, 2012. 